\title{
Aerosol Effects on Cloud Emissivity and Surface Longwave Heating in the Arctic
}

\author{
TIMOTHY J. GARRETT $1,{ }^{*}$, LAWRENCE F. RADKE $^{2}$, AND PETER V. HOBBS $^{1}$ \\ ${ }_{1}^{1}$ Atmospheric Sciences Department, University of Washington, Seattle, Washington
}

\author{
${ }^{2}$ National Center for Atmospheric Research, Boulder, Colorado
}

Submitted for publication to J. Atmos. Sci. (Special Issue on Global Aerosol Climatology): 12 December 2000

Revised manuscript submitted: 7 June 2001

Corresponding author: Peter V. Hobbs

University of Washington

Department of Atmospheric Sciences

Box 351640

Seattle, WA 98195-1640

Tel: (206) 543-6027

Fax: (206) 685-7160

E-mail: phobbs@atmos.washington.edu

\footnotetext{
* Now at Meteorology Department, University of Utah
} 


\begin{abstract}
Increases in anthropogenic aerosols in the atmosphere tend to increase the reflectance of solar (shortwave) radiation from water clouds, which can lead to lower surface temperatures. Here we discuss an opposing effect whereby aerosols increase the longwave emissivity of thin clouds, which adds to the warming of the Earth's surface. The latter effect may be particularly important in the Arctic, especially during the winter and early spring when thin stratus clouds are ubiquitous, relatively high levels of anthropogenic pollution are common, and there is little solar radiation.
\end{abstract}




\section{Introduction}

Clouds affect the climate of the Arctic primarily by increasing the amount of solar radiation reflected to space, and by absorbing and emitting longwave (thermal) and shortwave (solar) radiation. Globally, the net radiative impact of clouds is to cool the troposphere and the Earth's surface. However, modeling (Curry and Ebert 1992; Beesley 1997) and observational (Herman 1980; Stone 1997) studies show that in the Arctic cloud cover generally acts to warm the surface, while cooling the troposphere only slightly: clouds trap outgoing longwave radiation, but have a small impact on atmospheric albedo due to the high surface albedo of snow-covered land and sea ice. Radiative forcing by clouds depends foremost on cloud fractional cover and temperature, but also on cloud bulk radiative properties (i.e., the reflectivity, transmissivity, and emissivity of the cloud). Arctic stratus clouds are often sufficiently thin to have an emissivity less than unity (i.e., they are not blackbodies). Modeling studies (Curry and Ebert 1992) suggest that ignoring the transparency of arctic clouds to longwave radiation can lead to significant errors when estimating their radiative forcing. In view of evidence indicating that there has been rapid warming of the arctic surface in recent decades (Bradley et al. 1993; Stone 1997), improved understanding of the radiative properties of arctic clouds is critical to understanding the changing climate of the Arctic.

Cloud radiative properties can be altered by anthropogenic aerosols. A link between anthropogenic aerosol concentrations and cloud droplet spectra was suggested by Lewis (1951), who measured higher droplet concentrations and smaller droplet radii in low and middle-level stratiform clouds over the continental United States than over the Pacific Coast. Similar observations for maritime and continental cumulus clouds were reported by Squires (1956, 1958). Twomey $(1974,1977)$ proposed that aerosols might affect the shortwave radiative properties of clouds since, if cloud liquid water content (LWC) remains constant, an increase in cloud condensation nuclei $(\mathrm{CCN})$ concentrations, and therefore an increase in droplet concentrations, should produce increases in cloud optical depth and albedo. The susceptibility of cloud albedo to changes in cloud droplet concentrations (and therefore $\mathrm{CCN}$ concentrations) is 
greatest for clean clouds (droplet concentrations of $\sim 10 \mathrm{~cm}^{-3}$ ), where the albedo increases by about $1 \%$ for every increase in cloud droplet concentration of $1 \mathrm{~cm}^{-3}$ (Twomey 1991).

The effects of anthropogenic aerosols on maritime stratiform clouds have been measured from satellites and aircraft. For example, diesel-powered commercial ships, burning low-grade marine fuel oil, emit $\sim 1 \times 10^{16}$ particles per second (Hobbs et al. 2000). Approximately $12 \%$ of these particles act as CCN in overlying stratus and stratocumulus clouds (Hudson et al. 2000). Advection of this pollution downwind of a ship can produce long-lived 'shiptracks', several hundreds kilometers in length, in which the shiptrack appears brighter than the surrounding cloud in $3.7 \mu \mathrm{m}$ wavelength satellite imagery. In situ measurements show that if the ambient cloud is initially clean, enhanced droplet concentrations, smaller droplets, diminished drizzle flux, higher LWC, and higher values of shortwave reflectivity can occur within shiptracks (e.g., Durkee et al. 2000).

While increases in cloud droplet concentrations and decreases in droplet size, produced by increases in anthropogenic aerosols, increase the reflectivity of shortwave solar radiation, they also increase the emissivity of thin clouds and therefore the longwave radiation emitted upward and downward by these clouds (Curry and Ebert 1992; Curry et al. 1993; Zhang et al. 1996). If a cloud is cooler (warmer) than the surface, an increase in cloud emissivity would cool (warm) the Earth's surface and warm (cool) the troposphere. Since arctic liquid water clouds thicker than about $350 \mathrm{~m}$ have emissivities close to unity (Herman 1980), they will not be very susceptible to this effect.

The relative importance of cooling and warming of the Earth's surface due to increases in cloud reflectivity and emissivity, respectively, produced by increasing anthropogenic aerosols, will depend on a number of factors, including the thickness, temperature, location and coverage of the cloud, and how much solar radiation is reflected from the underlying surface. Cooling due to enhanced cloud reflectivity occurs only during daylights hours, whereas, warming due to increased cloud emissivity is most effective at night and at low sun angles. The latter set of conditions is particularly prevalent in the Arctic from fall through spring. 
In this paper we use airborne data, collected aboard the University of Washington CV-580 research aircraft in late spring 1998 during the FIRE-ACE/SHEBA field study (Curry et al., 2000), to evaluate the effectiveness of anthropogenic aerosols in increasing the emissivities of arctic clouds. We then consider possible implications for the longwave radiation balance of arctic surface.

\section{Sensitivity of Cloud Emissivity to Cloud Microstructure \\ a. Theory}

To determine the effect of an increase in aerosol on cloud emissivity, we must evaluate the sensitivity of cloud emissivity to the microstructures of a cloud. Conservation of energy requires the sum of cloud emissivity (due to absorption), transmissivity and reflectivity (due to scattering) be unity, that is:

$$
\varepsilon+t+r=1
$$

Herman (1980) obtained an accurate expression for cloud emissivity, derived from Chandrasekhar's first approximation (Chandrasekhar 1960) for two-stream radiative transfer. Herman (1980) showed the monochromatic upward and downward monochromatic intensities, $N^{+}$and $N$, respectively, can be obtained from the solution to the inhomogeneous second-order diffusivity equation:

$$
\frac{d^{2} \psi}{d \tau_{a b s}}-\beta^{2} \psi=-2 \sqrt{3}\left(d B_{\lambda} / d \tau_{a b s}\right)
$$

where, $\psi=N^{+}-N^{-}, \mathcal{B}_{\lambda}$ is the thermal source function at wavelength $\lambda, \tau_{\mathrm{abs}}$ is the absorption optical depth of the cloud (defined such that $\tau_{\mathrm{abs}}=0$ at cloud top), and $\beta$ is the diffusion factor: 


$$
\beta^{2}=3\left(1-\omega_{0} g\right) /\left(1-\omega_{0}\right)
$$

where, $\omega_{0}$ and $g$, are the single-scattering albedo and asymmetry parameter, respectively. Since the intensity is the sum of both emitted and scattered components (i.e., $N=N_{\text {emit }}+N_{\text {scat }}$ ), it can be shown from Eq. (2) that in the case of an homogeneous, isothermal cloud layer with temperature $T_{\mathrm{c}}$ :

$$
\varepsilon_{\lambda}=\frac{N_{\text {emit }}^{-}(\tau)}{B_{\lambda}\left(T_{c}\right)}=1-\frac{\left(3-\beta^{2}\right)\left(1-e^{-2 \beta \tau_{a b s}}\right)-4 \sqrt{3} \beta e^{-\beta \tau_{a b s}}}{(\sqrt{3}-\beta)^{2} e^{-2 \beta \tau_{a b s}}-(\sqrt{3}+\beta)^{2}}
$$

Note that in the absence of scattering, $\beta=1.73$, and:

$$
\varepsilon_{\lambda}=1-e^{-\beta \tau_{\mathrm{abs}}}
$$

which is equivalent to an expression for cloud emissivity frequently assumed in remote sensing and climate modeling applications, except that the diffusion factor, $\beta$, used here is typically replaced by the diffusivity factor $r \approx 1.66$ (Goody 1964), which is used to simplify angular integration of intensity over a hemisphere. At infrared wavelengths, scattering by cloud droplets is generally small compared to absorption. An estimated value for $\beta$ for arctic clouds is $1.8 \pm 0.2$, in which case broadband reflectivity approaches a maximum value for thick clouds of $2( \pm 5) \%$ (Herman 1980).

Our purpose here is to illustrate the sensitivity of absorption optical depth (and hence cloud emissivity) to cloud microphysical properties. The absorption optical depth may be determined from:

$$
\tau_{\mathrm{abs}}=\pi \int_{0}^{h} \int_{0}^{\infty} Q_{\mathrm{abs}}(r, z, \lambda) r^{2} N(r, z) d r d z
$$


where, $N(r, z)$ is the droplet number concentration as a function of radius $(r)$ of the droplet and height ( $z$ ) in a cloud of thickness $h, Q_{\mathrm{abs}}$ is the absorption efficiency, and $\lambda$ the wavelength of the radiation. Assuming a vertically homogeneous cloud, and using expressions for the cloud liquid water path $(L W P)$ and cloud droplet effective radius $\left(r_{\mathrm{e}}\right)$, Eq. 6 can be written as:

$$
\tau_{\mathrm{abs}}=\frac{3 Q_{\mathrm{abs}}\left(r_{e}, \lambda\right) L W P}{4 \rho r_{e}}
$$

where, $\rho$ is the density of liquid water.

At long wavelengths, the absorption efficiency, $Q_{\mathrm{abs}}$, depends strongly on droplet size and wavelength. For example, at a terrestrial wavelength of $11 \mu \mathrm{m}$ the imaginary component of the refractive index of water varies by almost an order of magnitude for $\Delta \lambda=4 \mu \mathrm{m}$ (Hale and Querry 1973). The amplitude of an electromagnetic wave propagating in the $z$ direction through an absorbing material is proportional to $e^{i(\omega t-m k z)}$, where $\omega$ is the angular frequency of the wave, $t$ time, $k=2 \pi / \lambda$ is the wavenumber, and $m=n-i n^{\prime}$ is the refractive index. Therefore, the magnitude of the Poynting vector, which determines the intensity of the wave, incident on a droplet of radius $r$, is attenuated by $e^{-4 \pi h^{\prime} r / \lambda}$ (van de Hulst 1981). For cloud droplets at infrared wavelengths, $4 \pi n^{\prime}$ is typically on the order of unity. Hence, for small values of $r / \lambda$, the attenuation of a Poynting vector incident on a droplet is roughly proportional to droplet size (Fig. 1). In this case, the absorption cross-section, $C_{\mathrm{abs}}$, is approximately proportional to the droplet volume. That is,

$$
Q_{\mathrm{abs}} \propto r \quad[r / \lambda \text { small }]
$$


For large values of $r / \lambda$, radiation incident on a droplet is absorbed within a droplet "penetration depth," and the absorption efficiency is roughly independent of droplet size (Fig. 1); $C_{\text {abs }}$ is then approximately proportional to the geometric cross-sectional area of the droplet. Therefore,

$$
Q_{\mathrm{abs}} \cong 1 \quad[r / \lambda \text { large }]
$$

The proportionalities discussed above are only approximate due, in part, to the diffraction of light incident on a droplet. Some of the Poynting vectors that are not immediately incident on a droplet deviate sufficiently from their original directions to be bent into the droplet, thereby enhancing the values of $Q_{\mathrm{abs}}$ (Bohren and Huffman 1998). This is particularly the case when $r / \lambda \lesssim 1$. As $r / \lambda$ increases in magnitude this effect becomes progressively less, so $Q_{\mathrm{abs}}$ asymptotically approaches a value of unity.

The effects on cloud absorption optical depth of the phenomena discussed above can be illustrated as follows. The absorption efficiency of cloud droplets with respect to terrestrial radiation depends on the sizes of the droplets and the wavelength of the incident radiation. The peak in the intensity of the radiation emitted by the Earth lies between wavelengths of about 10 and $12 \mu \mathrm{m}$. In many clouds the peak in the droplet size distribution lies at $r<10 \mu \mathrm{m}$. In this case, to a good approximation, $Q_{\mathrm{abs}}=a r_{\mathrm{e}}$, where $a$ is a constant. Substituting this expression into Eq. (7), yields:

$$
\tau_{\mathrm{abs}}=\frac{3 a_{\lambda} L W P}{4 \rho}
$$

in which case, $\tau$ depends only on the bulk properties of the cloud (i.e., $L W P$ ) and not on its microstructure. On the other hand, for some clouds the peak in the droplet size distribution is at $\mathrm{r}$ $>10 \mu \mathrm{m}$. In this case, $Q_{\mathrm{abs}} \cong 1$, and: 


$$
\tau_{\mathrm{abs}}=\frac{3 L W P}{4 \rho r_{e}}
$$

in which case the absorption optical depth depends on both $L W P$ and $r_{\mathrm{e}}$.

Below we will derive precise expressions for $\beta \tau_{\text {abs }}$ (the term in the exponent of Eq. (4)) and $\beta$ as a function of $L W P$ and $r_{\mathrm{e}}$ that are representative of a) the shape of typical droplet spectra in arctic clouds, and b) the shape of the terrestrial blackbody spectrum. These will then be used to calculate the emissivity of arctic clouds.

\section{b. $\quad$ Measurements}

We will use 2156 measurements of droplet spectra obtained in six regions of arctic stratus clouds sampled between 6 June and 14 June 1998 over the Arctic Ocean. These measurements comprised droplet spectra with a wide range of droplet effective radii and droplet spectra dispersions. The measurements were obtained aboard the University of Washington's Convair-580 research aircraft in FIRE-ACE/SHEBA using PMS FSSP-100 and PMS OAP-200X probes to measure the size distribution of droplets between 1 and $150 \mu \mathrm{m}$. The FSSP-100 and OAP-200X were calibrated before, during and after FIRE-ACE/SHEBA. The optical parameters $Q_{\mathrm{abs}}, g$, and $\omega_{0}$ were calculated from explicit Mie code for each droplet spectrum, and for 40 wavelengths between 5 and $90 \mu \mathrm{m}$.

Figures 2 shows a plot of $\beta Q_{\text {abs }}$ and $\beta$ versus $r_{\mathrm{e}}$ at $11 \mu \mathrm{m}$, where $\beta$ is calculated from Eq. (2). There is some scatter in the data because $r_{\mathrm{e}}$ does not correspond to a single value of $\beta$ or $\beta Q_{\mathrm{abs}}$, due to variability in the shape of the size distributions of droplets. Nonetheless, $\beta Q_{\mathrm{abs}}$ and $\beta$ show a well-defined dependence on $r_{\mathrm{e}}$, although $\beta$ is approximately constant for the range of $r_{\mathrm{e}}$ shown. The coefficients of a first order exponential fit to $\beta$, and a seventh order polynomial fit to the $\beta Q_{\text {abs }}$ (cf. Chy' lek et al. 1992), at each wavelength, are shown in Tables 1 and 2, respectively, where: 


$$
\beta=\beta_{0 \lambda}+A_{\lambda} e^{-\left(r_{e}-3.7\right) / B_{\lambda}}
$$

and,

$$
\beta Q_{\mathrm{abs}}=\sum_{N=0}^{N=7} a_{N \lambda} r_{e}^{N}
$$

in which case, from Eqns. (7) and (13):

$$
\beta \tau_{a b s}\left(L W P, r_{e}, \lambda\right)=-\frac{3 L W P}{4 \rho} \sum_{N=0}^{N=7} a_{N}(\lambda) r_{e}^{N-1}
$$

Using the values of the coefficients given in Tables 1 and 2, and substituting Eqs. (12) and (14) into Eq. (4), yields a numerical expression for $\varepsilon\left(L W P, r_{\mathrm{e}}, \lambda\right)$ that provides accurate values for the cloud emissivity as a function of cloud droplet effective radius and liquid water path in isothermal, homogeneous arctic clouds.

The broadband emissivity for a cloud with a temperature of $250 \mathrm{~K}$ (calculated by weighting the numerical expression derived for Eq. 4 by the Planck function wavelength dependent intensity at $250 \mathrm{~K}$ ) is shown in Fig. 3. The broadband emissivity approaches a maximum value of $\sim 0.96$ for clouds with $L W P$ greater than $\sim 40 \mathrm{~g} \mathrm{~m}^{-2}$ (e.g., a stratiform cloud $200 \mathrm{~m}$ thick with a mean $L W C$ of $0.2 \mathrm{~g} \mathrm{~m}^{-3}$ ), the remainder being infrared energy reflected by the cloud. For thinner clouds, $\varepsilon$ is less than 0.96 and it is therefore sensitive to the sizes of the cloud droplets (e.g., for a $L W P$ of $10 \mathrm{~g} \mathrm{~m}^{-2}, \mathrm{~d} \varepsilon / \mathrm{d} r_{\mathrm{e}} \cong-0.024 \mu \mathrm{m}^{-1}$ ).

\section{Effects of Aerosols on Cloud Microstructure in the Arctic}

On 14 June 1998, the Convair-580 research aircraft flew a straight and level $84 \mathrm{~km} \mathrm{leg}$ over the Chukchi Sea through the middle of a stratiform cloud layer $\sim 200 \mathrm{~m}$ thick with cloud top $400 \mathrm{~m}$ above sea level. There was a gradual transition between pristine air, with low total particle 
concentrations (droplet + interstitial aerosols), to more polluted air with particle concentrations twice as high (Fig. 4). Along the same track the mean cloud droplet concentrations (obtained from the FSSP-100) increased from 29 to $77 \mathrm{~cm}^{-3}$ and the cloud droplet effective radius (obtained from the FSSP-100 and PMS OAP-200X) decreased from 12.5 to $8.8 \mu \mathrm{m}$. The drizzle flux (calculated from PMS OAP-2DC measurements aboard the Convair-580) in the cleaner portion of the cloud was $0.86 \pm 1.3 \mathrm{~mm} /$ day, but this flux was effectively zero in the more polluted cloud. The total $L W C$ (cloud + precipitation) from the FSSP-100 and PMS OAP-200X increased from $0.15 \pm 0.05$ to $0.25 \pm 0.01 \mathrm{~g} \mathrm{~m}^{-3}$ in passing from the clean to the polluted cloud. No measurements were obtained of the vertical wind field within the cloud, which may influence cloud microstructures, however temperature, pressure and dewpoint were constant along the flight leg, so it appears reasonable to assume the dynamic conditions were constant as well.

These results demonstrate a high sensitivity of arctic clouds to pollution. This is because arctic clouds are generally among the cleanest in the world. Cloud droplet concentrations occasionally as low as $5 \mathrm{~cm}^{-3}$ were measured from the Convair-580 during FIRE-ACE/SHEBA. Thus, the addition of even low concentrations of anthropogenic CCN can cause substantial reductions in droplet size and cloud precipitation and increases in $L W C$. Airmass back trajectories (obtained from the NOAA Air Resources Laboratory) indicate that the airmass sampled on 14 June 1998 came from the east, possibly passing over the Prudhoe Bay oil drilling site. Therefore, the increase in aerosol that affected the cloud we sampled on 14 June could have been of local anthropogenic origin. However, as elevated layers of arctic haze were frequently encountered during these studies, the enhanced aerosol on 14 June could also have derived from long-range transport of anthropogenic pollution.

\section{Implications for the arctic surface radiation balance}

The radiative properties of arctic clouds are important to the radiation balance of the Arctic (Fig. 5) and they are sensitive to cloud microphysical structures. Clouds reduce the solar

flux absorbed at the surface by about $0 \mathrm{~W} \mathrm{~m}^{-2}$ in winter, when solar flux is small or zero, and by 
about $64 \mathrm{~W} \mathrm{~m}^{-2}$ in July when days are long. Clouds enhance the net longwave flux at the arctic surface by between about 25 and $63 \mathrm{~W} \mathrm{~m}^{-2}$, with the higher values occurring in late spring and summer because of greater cloud coverage (Vowinckel and Orvig 1964). Because cloud shortwave radiative forcing is more seasonal than the longwave forcing, clouds strongly warm the surface of the Arctic in the dark months, but cool the surface very weakly in July. In late spring and summer, low-level stratiform clouds in the Arctic have LWP that are usually greater than $20 \mathrm{~g} \mathrm{~m}^{-2}$ (Fig. 7c) (Herman and Curry 1984; Tsay and Jayaweera 1984; Hobbs and Rangno 1998). For this range of LWP, a reduction in $r_{\mathrm{e}}$ (e.g., from increased pollution) increases shortwave cooling more than longwave warming. (Curry et al. 1993; Zhang et al. 1996).

In winter and early spring, days are short and the solar flux is small or zero in the Arctic. Under these conditions, a transition from clear sky to low-level cloud cover can cause sudden surface warming by dramatically increasing downwelling longwave radiation (Stone 1997). Low-level clouds have a brightness temperature much greater than that of a clear sky, particularly as the arctic winter is characterized by a nearly permanent low-level temperature inversion of $\sim 10^{\circ} \mathrm{C}$ (Kahl 1990). In winter, the clouds cause little to no compensating cooling, due to the absence of sunlight. In addition, anthropogenic pollution advected to the Arctic from lower latitudes is greatest in winter and spring (see Fig. 5) (e.g., Barrie 1986; Sirois and Barrie 1999). It is difficult to estimate how combined high levels of pollution and low clouds will affect arctic night cloud emissivity since, to our knowledge, there have been no published measurements of $L W P$ or $r_{\mathrm{e}}$ in wintertime arctic clouds. However, in spring 1992 thirty-six profiles of the lower troposphere were obtained over the Beaufort Sea from the UW Convair C-131A research aircraft (Hobbs and Rangno 1998). We will assume that these measurements are approximately representative of wintertime low-level clouds in the Arctic. Fifteen of the profiles measured by Hobbs and Rangno consisted of water clouds (with an average $L W P$ of $4 \mathrm{~g}$ $\mathrm{m}^{-2}$ and an average cloud top temperatures of about $-20^{\circ} \mathrm{C}$ ) overlaying tenuous ice crystal precipitation (with an average IWP of $1 \mathrm{~g} \mathrm{~m}^{-2}$ ) (Fig. 6). These supercooled water clouds can be maintained, even at temperatures below $-30^{\circ} \mathrm{C}$, by an imbalance between the supply of vapor and 
the mass growth rate of ice crystals, which occurs due to the small sizes of ice crystals near cloud top (Rauber and Tokay 1991). Although changes in ice crystal size have little impact on cloud emissivity (Curry et al. 1993), the mean LWP is sufficiently thin that changes in the cloud droplet effective radius $\left(r_{\mathrm{e}}\right)$ will perturb cloud longwave radiative properties. Measurements near Igloolik, NWT, Canada, in February 1982, indicate CCN concentrations of $\sim 80 \mathrm{~cm}^{-3}$ for stratiform clouds in polluted air, compared to $\sim 30 \mathrm{~cm}^{-3}$ in cleaner air (Leaitch et al. 1984). A corresponding change in droplet concentration for the example shown in Fig. 4, causes a reduction in $r_{\mathrm{e}}$ of $4 \mu \mathrm{m}$. Hence, the combination of thin clouds, darkness, and anthropogenic pollution in the Arctic during winter and spring provide a scenario in which an increase in cloud emissivity could significantly increase downwelling longwave radiation and warm the surface.

To address this possibility more quantitatively, we simulated radiative transfer in the arctic atmosphere using the Streamer radiative transfer code (Key and Schweiger 1998). Streamer incorporates temperature, gas and aerosol profiles; cloud height, cover and microphysical properties; and surface type and albedo into a column model to calculate profiles of radiative fluxes for 105 infrared and 15 shortwave bands. Streamer does not perform accurate "line-by-line" gaseous absorption calculations. However, an advantage of Streamer is that it allows the user to explicitly define the effective cloud droplet radius, liquid water content and thickness of a cloud. Streamer then uses built-in parameterizations to convert cloud microphysical properties to optical parameters. These parameters are used to calculate, using two or more streams, radiative transfer in a cloud using a discrete ordinates solver. The scattering phase function is defined by the asymmetry parameter and the Henyey-Greenstein phase function, with or without forward truncation. In the analysis described here, fluxes are calculated using $\delta$-M truncation of the phase function (Wiscombe 1977) and a four-stream flux model (Stamnes 1988). To illustrate the results of these calculations we will describe a case study that utilizes data described by Hobbs and Rangno (1998) (their Profile 3 for 2346 UTC 3 April 1992), which had a $L W P$ of $12 \mathrm{~g} \mathrm{~m}^{-2}$, a cloud top temperature of $-19^{\circ} \mathrm{C}$, and $0.4 \mathrm{~g} \mathrm{~m}^{-2}$ of "diamond dust" below cloud base (Fig. 6). The effective radius of the diamond dust ice crystals was set at $40 \mu \mathrm{m}$. 
Between altitudes of 0 and $5 \mathrm{~km}$ we used the rawinsonde temperature and humidity profile from Barrow, Alaska, at 00Z 4 April 1992. A standard arctic winter atmosphere was used to extend the profile to higher levels. The surface temperature was about $-20^{\circ} \mathrm{C}$.

Cloud radiative forcing at the surface $(C R F$ (surface) $)$ can be defined as the instantaneous difference between the irradiance (in $\mathrm{W} \mathrm{m}^{-2}$ ) at the surface with and without cloud being present. Figure $7 \mathrm{a}$ shows that the cloud radiative forcing at the surface for longwave radiation $\left(C R F_{\mathrm{LW}}(\right.$ surface $\left.)\right)$ is sensitive to the microstructure of the cloud. The maximum sensitivity for clouds with an initial droplet effective radius $r_{\mathrm{e}}$ of $10 \mu \mathrm{m}$ occurs for clouds with $L W P$ of $\sim 8 \mathrm{~g} \mathrm{~m}^{-2}$, where $-\mathrm{d}\left(C R F_{\mathrm{LW}}(\right.$ surface $\left.)\right) / \mathrm{d} r_{\mathrm{e}}=1.75 \mathrm{~W} \mathrm{~m}^{-2} \mu \mathrm{m}^{-1}$. The sensitivity of $C R F$ (surface) to $r_{\mathrm{e}}$ falls off gradually for thicker clouds and rapidly for thinner clouds. The maximum sensitivity is largest for clouds with small initial values of $r_{\mathrm{e}}$ and small $L W P$. For the example shown in Fig. 6 a decrease in $r_{\mathrm{e}}$ of $4 \mu \mathrm{m}$ (such as that shown in Fig. 4) would increase downwelling longwave radiation by $\sim 7 \mathrm{~W} \mathrm{~m}^{-2}$. If pollution throughout the Arctic should decrease $r_{\mathrm{e}}$ by $4 \mu \mathrm{m}$ in low and middle-level clouds, which cover about $50 \%$ of the Arctic Ocean from late autumn through early spring (Warren et al. 1988), and the LWP was such that $\mathrm{d}\left(C R F_{\mathrm{LW}}(\right.$ surface $\left.)\right) / \mathrm{d} r_{\mathrm{e}}$ was at a maximum, the average increase in downwelling longwave radiation in winter in the Arctic could be as much as $3 \mathrm{~W} \mathrm{~m}^{-2}$.

The past 30 years in the Arctic have been characterized by increasing February surface temperatures (Stone 1997) and higher levels of pollution (Sirois and Barrie 1999). It is possible that the increase in arctic surface temperatures could be due, in part, to the effects of increases in aerosol on cloud emissivity. For example, if the surface were to respond as a blackbody to increased downwelling longwave radiation, an average increase in downwelling radiation of $3 \mathrm{~W}$ $\mathrm{m}^{-2}$ would produce an increase in surface temperatures of $0.8^{\circ} \mathrm{C}$ (assuming no compensating effects, such as tropospheric adjustments to changes in cloud emissivity). Temperature profiles in winter and early spring in the Arctic are characterized by low-level temperature inversions $\sim 800$ $\mathrm{m}$ deep with a temperature difference of $\sim 10^{\circ} \mathrm{C}$ (Kahl 1990). Consequently, wintertime arctic clouds are usually warmer than the underlying surface. Therefore, any increase in cloud 
emissivity will augment outgoing longwave radiation at the top of the atmosphere. Hence, although an increase in aerosol might warm the surface due to the aerosol effect on cloud emissivity, it could cool the atmosphere as a whole. However, for typical values of the temperature difference across the inversion, the cooling of the atmosphere is relatively small compared to the warming at the surface. For example, if the surface temperature were changed from $-20^{\circ} \mathrm{C}$ to $-30^{\circ} \mathrm{C}$ for the case shown in Fig. 6 (i.e., there was an $11^{\circ} \mathrm{C}$ temperature difference between the surface and the cloud, instead of $1^{\circ} \mathrm{C}$ ), and the initial value of $r_{\mathrm{e}}$ is $10 \mu \mathrm{m}$, the sensitivity of $C R F_{\mathrm{LW}}(\mathrm{TOA})$ to $r_{\mathrm{e}}$ has a maximum value for $L W P=8 \mathrm{~g} \mathrm{~m}^{-3}$ where $-\mathrm{d}\left(C R F_{\mathrm{LW}}(\mathrm{TOA})\right) / \mathrm{d} r_{\mathrm{e}}=-0.2 \mathrm{~W} \mathrm{~m}^{-2} \mu \mathrm{m}^{-1}$.

As mentioned previously, the above discussion is concerned with instantaneous radiative forcings and does not include various feedbacks that might be introduced by an increase in cloud emissivity and cloud top radiative cooling. For example, low-level arctic clouds are frequently radiatively (rather than convectively) driven, and an increase in cloud-top radiative cooling might further augment their emissivity by increasing cloud thickness. On the other hand, an increase in radiative cooling at cloud top could decrease the strength of an inversion, decrease cloud temperature, and thereby reduce longwave surface warming. Increases in $C R F_{\mathrm{LW}}$ due to pollution could also increase cloud $L W P$ (note the increase in $L W C$ in the polluted region shown in Fig. 4) and cloud lifetimes (Albrecht 1989). Clearly, a detailed study of the effects of changes in the emissivity of arctic clouds, due to changes in aerosol, on the overall radiative balance of the Arctic will require the use of a detailed climate model. Furthermore, our demonstration that the microstructures of arctic clouds are sensitive to aerosol concentrations, is based on limited data obtained during the late arctic spring. Interactions between aerosols, clouds and radiation need to be studied during the dark months, when longwave effects dominate.

Acknowledgments. This research was supported by the NASA Radiation Science Program through grants NAG1-2079 and NAG5-7675 to the University of Washington. NCAR is sponsored by the National Science Foundation. 


\section{REFERENCES}

Albrecht, B. A., 1989: Aerosols, cloud microphysics, and fractional cloudiness. Science, 245, 1227-1230.

Barrie, L. A., 1986: Arctic air pollution: An overview of current knowledge. Atmos. Environ., 20, 643-663.

Beesley, J. A., 1997: The Climatic Effects and Requirements of Arctic Clouds. Ph.D. Dissertation, University of Washington, 108pp.

Bohren, C. F., and D. R. Huffman, 1998: Absorption and Scattering of Light by Small Particles, Wiley, $530 \mathrm{pp}$.

Bradley, R. S., F. T. Keimig, and H. F. Diaz, 1993: Recent changes in the North American Arctic boundary layer in winter. J. Geophys. Res., 98, 8851-8858.

Chandrasekhar, S., 1960: Radiative Transfer. Dover, 393 pp.

Chýlek, P., P. Damiano, and E. P. Shettle, 1992: Infrared emittance of water clouds. J. Atmos. Sci., 49, 1459-1472.

Curry, J. A., and E. E. Ebert, 1992: Annual cycle of radiation fluxes over the Arctic Ocean: Sensitivity to cloud optical properties. J. Climate., 5, 1267-1280. , and G. F. Herman, 1985: Infrared radiative properties of summertime arctic clouds. J. Climate. Appl. Met., 24, 525-538. , P. V. Hobbs, M. D. King, D. A. Randall, P. Minnis, G. A. Isaac, J. O. Pinto, T. Uttal, A. Bucholtz, D. G. Cripe, H. Gerber, C. W. Fairall, T. J. Garrett, J. Hudson, J. M. Intrieri, C. Jakob, T. Jensen, P. Lawson, D. Marcotte, L. Nguyen, P. Pilewskie, A. Rangno, D. C. Rogers, K. B. Strawbridge, F.P.J. Valero, A. G. Williams, and D. Wylie, 2000: FIRE arctic clouds experiment. Bull. Amer. Meteor. Soc., 81, 5-29. , J. L. Schramm, and E. E. Ebert, 1993: Impact of clouds on the surface radiation balance of the ocean. Meteor. Atmos. Phys., 51, 197-217. 
Durkee, P., K. Nielsen, R. J. Ferek, T. J. Garrett, P. V. Hobbs, C. S. Bretherton, H. Rand, D. W. Johnson, J. P. Taylor, S. R. Osborne, J. Hudson, G. M. Frick, W. A. Hoppel, G. Innis, C. O’Dowd, K. Noone, E. Ostrom, R. Flagan, L. M. Russell, J. Seinfeld, and R. Gasparovic, 2000: The impact of aerosols from ships on the microstructure and albedo of warm marine stratocumulus clouds. J. Atmos. Sci., 57, 2554-2569.

Goody, R. M., 1964: Atmospheric Radiation, Oxford University Press, 519 pp.

Hale, G. M., and M. R. Querry, 1973: Optical constants of water in the $200 \mathrm{~nm}$ to $200 \mu \mathrm{m}$ wavelength region. Appl. Opt., 12, 555-563.

Herman, G. F., 1980: Thermal radiation in arctic stratus clouds. Q.J.R. Meteorol. Soc. 106, 771780. , and J. A. Curry, 1984: Observational and theoretical studies of solar radiation in arctic stratus clouds. J. Climate Appl. Meteor., 23, 5-23.

Hobbs, P. V., and A. L. Rangno, 1998: Microstructures of low and middle-level clouds over the Beaufort Sea. Q. J. R. Meteorol. Soc., 124, 2035-2071. , and __ 2000: Ice particles in stratiform clouds in the Arctic and possible mechanisms for the production of high ice concentrations. J. Geophys. Res. (in press). , T. J. Garrett, R. J. Ferek, S. R. Strader, D. A. Hegg, G. M. Frick, W. A. Hoppel, R. F. Gasparovic, L. M. Russell, D. W. Johnson, C. O’Dowd, P. A. Durkee, K. E. Nielsen, and G. Innis, 2000: Emissions from ships with respect to their effects on clouds. J. Atmos. Sci., 57, 2570-2590,.

Hudson, J. G., T. J. Garrett, P. V. Hobbs, S. R. Strader, Y. Xie, and S. S. Yum, 2000: Cloud condensation nuclei and ship tracks. J. Atmos. Sci., 57, 2696-2706.

Kahl, J. D., 1990: Characteristics of the low-level temperature inversion along the Alaskan arctic coast. Int. J. Climatol., 10, 537-548.

Key, J., and A. J. Schweiger, 1998: Tools for atmospheric radiative transfer: Streamer and FluxNet. Computers \& Geosciences, 24, 443-451. 
Leaitch, W. R., R. M. Hoff, S. Melnichuk, and A.W. Hogan, 1984: Some physical and chemical properties of arctic winter aerosol in northeastern Canada. J. Clim. Appl. Meteorol., 23, 916-928.

Lewis, W., 1951: Meteorological aspects of aircraft icing. In Compendium of Meteorology, T. F. Malone, Ed., American Meteorological Society, 1334 pp.

Pinto, J. O., 1998: Autumnal mixed-phase cloudy boundary layers in the Arctic. J. Atmos. Sci., 55, 2016-2038.

Rauber, R. M., and A. Tokay, 1991: An explanation for the existence of supercooled water at the top of cold clouds. J. Atmos. Sci., 48, 1005-1023.

Sirois, A., and L. A. Barrie, 1999: Arctic lower tropospheric aerosol trends and composition at Alert, Canada: 1980-1995. J. Geophys. Res., 104, 11599-11618.

Squires, P., 1956: The microstructure of cumuli in maritime and continental air. Tellus 8, 443444.

, 1958: The microstructure and colloidal stability of liquid water and droplet concentrations in cumuli. Tellus 10, 256-261.

Stamnes, K. S.-C. Tsay, W. Wiscombe, and K. Jayaweera, 1988: A numerically stable algorithm for discrete-ordinate-method radiative transfer in multiple scattering and emitting layered media. Appl. Opt., 27, 2502-2509.

Stone, R. S., 1997: Variations in western arctic temperatures in response to cloud radiative and synoptic-scale influences. J. Geophys. Res., 102, 21769-21776.

Tsay, S. C., and K. Jayaweera, 1984: Physical characteristics of arctic stratus. J. Climate. Appl. Meteor., 23, 584-596.

Twomey, S., 1974: Pollution and the planetary albedo. Atmos Environ., 8, 1251-1256. , 1977: The influence of pollution on the shortwave albedo of clouds. J. Atmos. Sci., 34, 1149-1152.

, 1991: Aerosols, clouds and radiation. Atmos. Environ., 25A, 2435-2442.

van de Hulst, H. L. 1981: Light Scattering by Small Particles Dover Publications, 470 pp. 
Vowinckel, E., and S. Orvig, 1964: Energy balance of the Arctic. Part II: Longwave radiation and total radiation balance at the surface in the Arctic. Arch. Met. Geoph. Biokl., B., 13, 451-479.

Warren, S. G., C. J. Hahn, J. London, R. M. Chervin, and R. Jenne, 1988: Global distribution of total cloud cover and cloud type amounts over the ocean. NCAR Tech. Note TN-317 STR, $212 \mathrm{pp}$.

Wiscombe, W., 1977: The delta-M method: rapid yet accurate radiative flux calculations. $J$. Atmos. Sci., 34, 1408-1422.

Zhang, T., K. Stamnes, and S. A. Bowling, 1996: Impact of clouds on surface radiative fluxes and snowmelt in the Arctic and Subarctic. J. Climate., 9, 2110-2123. 
TABLE 1. Coefficients ( $\left.\beta_{\mathrm{o} \lambda}, \mathrm{A}_{\lambda}, \mathrm{B}_{\lambda}\right)$ of a first-order linear exponential fit of $\beta$ to $r_{\mathrm{e}}$ (Eq. 12) calculated using Mie code for 2156 droplet spectra measured in arctic stratus clouds for 40 values of wavelength, $\lambda$.

\begin{tabular}{|c|c|c|c|c|c|c|c|}
\hline$\lambda(\mu \mathrm{m})$ & $\beta_{0 \lambda}$ & $\mathrm{A}_{\lambda}$ & $\mathrm{B}_{\lambda}(\mu \mathrm{m})$ & $\lambda(\mu \mathrm{m})$ & $\beta_{0 \lambda}$ & $\mathrm{A}_{\lambda}$ & $\mathrm{B}_{\lambda}(\mu \mathrm{m})$ \\
\hline 5 & 2.040 & 1.014 & 4.15 & 25 & 1.853 & 0.136 & 7.12 \\
\hline 6 & 1.776 & 0.091 & 3.01 & 26 & 1.853 & 0.140 & 7.95 \\
\hline 7 & 1.909 & 0.464 & 4.16 & 27 & 1.853 & 0.144 & 8.94 \\
\hline 8 & 1.926 & 0.413 & 4.63 & 28 & 1.852 & 0.147 & 10.11 \\
\hline 9 & 1.856 & 0.193 & 5.23 & 29 & 1.849 & 0.150 & 11.49 \\
\hline 10 & 1.767 & 0.043 & 5.63 & 30 & 1.846 & 0.154 & 13.13 \\
\hline 11 & 1.766 & 0.037 & 4.96 & 32 & 1.837 & 0.158 & 17.30 \\
\hline 12 & 1.771 & 0.032 & 4.03 & 34 & 1.825 & 0.158 & 23.13 \\
\hline 13 & 1.788 & 0.037 & 3.22 & 36 & 1.814 & 0.156 & 31.62 \\
\hline 14 & 1.803 & 0.050 & 3.38 & 38 & 1.805 & 0.153 & 44.72 \\
\hline 15 & 1.811 & 0.063 & 3.54 & 40 & 1.798 & 0.148 & 68.21 \\
\hline 16 & 1.819 & 0.074 & 3.64 & 42 & 1.935 & -0.067 & 1.33 \\
\hline 17 & 1.826 & 0.086 & 3.74 & 44 & 1.936 & -0.196 & 1.19 \\
\hline 18 & 1.832 & 0.098 & 3.90 & 46 & 1.938 & -0.212 & 1.24 \\
\hline 19 & 1.838 & 0.110 & 4.13 & 48 & 1.946 & -0.086 & 2.76 \\
\hline 20 & 1.841 & 0.118 & 4.50 & 50 & 1.949 & -0.251 & 1.47 \\
\hline 21 & 1.844 & 0.120 & 4.90 & 60 & 1.977 & -0.292 & 2.07 \\
\hline 22 & 1.847 & 0.125 & 5.34 & 70 & 2.011 & -0.336 & 3.00 \\
\hline 23 & 1.848 & 0.125 & 5.90 & 80 & 2.027 & -0.362 & 3.73 \\
\hline 24 & 1.851 & 0.132 & 6.44 & 90 & 2.030 & -0.368 & 4.45 \\
\hline
\end{tabular}


TABLE 2. Coefficients $\left(\mathrm{a}_{\mathrm{N}_{\lambda}}\right)$ of a seventh-order linear regression of $\beta Q_{\mathrm{abs}}$ to $r_{\mathrm{e}}$ (Eq. 13) calculated using Mie code for 2156 droplet spectra measured in arctic stratus clouds for 40 values of wavelength, $\lambda . r$ is the correlation coefficient for the least-squares polynomial fit to the data.

\begin{tabular}{lccccccccc}
\hline$\lambda(\mu \mathrm{m})$ & $\mathrm{a}_{0}$ & $\mathrm{a}_{1}$ & $\mathrm{a}_{2}$ & $\mathrm{a}_{3}$ & $\mathrm{a}_{4}$ & $\mathrm{a}_{5}$ & $\mathrm{a}_{6}$ & $\mathrm{a}_{7}$ & $\mathrm{r}^{2}$ \\
& & & $\left(\times 10^{-2}\right)^{*}$ & $\left(\times 10^{-3}\right)^{*}$ & $\left(\times 10^{-4}\right)^{*}$ & $\left(\times 10^{-5}\right)^{*}$ & $\left(\times 10^{-7}\right)^{*}$ & $\left(\times 10^{-10}\right)^{*}$ & \\
\hline 5 & -0.137 & 0.289 & -2.63 & 1.42 & -0.507 & 0.114 & -0.138 & -0.668 & 0.95 \\
6 & 0.168 & 0.648 & -8.70 & 6.00 & -2.33 & 0.507 & -0.571 & 2.55 & 0.84 \\
7 & -0.191 & 0.378 & -2.99 & 1.28 & -0.378 & -0.080 & -0.995 & -0.505 & 0.92 \\
8 & -0.123 & 0.287 & -1.52 & 0.362 & -0.057 & 0.019 & -0.409 & 0.278 & 0.92 \\
9 & 0.0090 & 0.175 & -0.28 & -0.378 & 0.157 & -0.014 & -0.016 & 0.204 & 0.93 \\
10 & 0.028 & 0.140 & -0.11 & -0.354 & 0.120 & -0.0036 & -0.269 & 0.249 & 0.94 \\
11 & -0.067 & 0.340 & -2.65 & 1.18 & -0.387 & 0.089 & -0.117 & 0.601 & 0.92 \\
12 & 0.104 & 0.56 & -7.02 & 4.72 & -1.84 & 0.406 & -0.466 & 2.12 & 0.89 \\
13 & 0.404 & 0.62 & -9.00 & 6.7 & -2.77 & 0.635 & -0.742 & 3.41 & 0.86 \\
14 & 0.587 & 0.685 & -10.5 & 7.92 & -3.27 & 0.741 & -0.855 & 3.89 & 0.87 \\
15 & 0.410 & 0.789 & -11.9 & 8.93 & -3.65 & 0.817 & -0.935 & 4.22 & 0.86 \\
16 & 0.292 & 0.868 & -13.1 & 9.8 & -3.98 & 0.888 & -1.01 & 4.55 & 0.86 \\
17 & 0.099 & 0.959 & -14.4 & 10.7 & -4.31 & 0.959 & -1.09 & 4.90 & 0.85 \\
18 & -0.141 & 1.05 & -15.5 & 11.4 & -4.57 & 1.01 & -1.14 & 5.13 & 0.84 \\
19 & -0.406 & 1.13 & -16.3 & 11.7 & -4.67 & 1.02 & -1.15 & 5.17 & 0.83 \\
20 & -0.657 & 1.17 & -16.3 & 11.5 & -4.49 & 0.975 & -1.09 & 4.86 & 0.83 \\
21 & -0.821 & 1.18 & -16.0 & 11.0 & -4.24 & 0.912 & -1.02 & 4.51 & 0.83 \\
22 & -0.973 & 1.19 & -15.7 & 10.6 & -4.01 & 0.854 & -0.944 & 4.17 & 0.84 \\
23 & -1.062 & 1.18 & -15.0 & 9.89 & -3.67 & 0.776 & -0.852 & 3.75 & 0.84 \\
& & & & & & & & & $(\mathrm{cont})$.
\end{tabular}


Table 2 (cont.)

\begin{tabular}{lccccccccc}
\hline$\lambda(\mu \mathrm{m})$ & $\mathrm{a}_{0}$ & $\mathrm{a}_{1}$ & $\mathrm{a}_{2}$ & $\mathrm{a}_{3}$ & $\mathrm{a}_{4}$ & $\mathrm{a}_{5}$ & $\mathrm{a}_{6}$ & $\mathrm{a}_{7}$ & $\mathrm{r}^{2}$ \\
& & & $\left(\times 10^{-2}\right)^{*}$ & $\left(\times 10^{-3}\right)^{*}$ & $\left(\times 10^{-4}\right)^{*}$ & $\left(\times 10^{-5}\right)^{*}$ & $\left(\times 10^{-7}\right)^{*}$ & $\left(\times 10^{-10}\right)^{*}$ & \\
\hline 24 & -1.19 & 1.189 & -14.8 & 9.49 & -3.48 & 0.723 & -0.786 & 3.44 & 0.85 \\
25 & -1.28 & 1.18 & -14.2 & 8.87 & -3.18 & 0.651 & -0.702 & 3.05 & 0.86 \\
26 & -1.34 & 1.15 & -13.4 & 8.12 & -2.83 & 0.569 & -0.605 & 2.61 & 0.86 \\
27 & -1.38 & 1.12 & -12.5 & 7.27 & -2.45 & 0.480 & -0.502 & 2.14 & 0.87 \\
28 & -1.40 & 1.07 & -11.5 & 6.34 & -2.04 & 0.385 & -0.392 & 1.65 & 0.87 \\
29 & -1.39 & 1.02 & -10.3 & 5.38 & -1.63 & 0.290 & -0.284 & 1.16 & 0.87 \\
30 & -1.36 & 0.963 & -9.14 & 4.37 & -1.19 & 0.193 & -0.173 & 0.665 & 0.88 \\
32 & -1.26 & 0.842 & -6.89 & 2.54 & -0.431 & 0.023 & 0.019 & -0.185 & 0.89 \\
34 & -1.14 & 0.740 & -5.11 & 1.14 & 0.138 & -0.102 & 0.157 & -0.791 & 0.89 \\
36 & -1.05 & 0.672 & -3.94 & 0.232 & 0.506 & -0.182 & 0.245 & -1.17 & 0.89 \\
38 & -0.978 & 0.622 & -3.07 & -0.452 & 0.786 & -0.244 & 0.313 & -1.48 & 0.90 \\
40 & -0.939 & 0.595 & -2.55 & -0.892 & 0.973 & -0.285 & 0.362 & -1.69 & 0.90 \\
42 & -0.910 & 0.570 & -2.00 & -1.38 & 1.18 & -0.335 & 0.418 & -1.95 & 0.90 \\
44 & -0.897 & 0.553 & -1.52 & -1.84 & 1.40 & -0.386 & 0.478 & -2.22 & 0.90 \\
46 & -0.876 & 0.528 & -0.905 & -2.41 & 1.66 & -0.447 & 0.550 & -2.54 & 0.90 \\
48 & -0.847 & 0.498 & -0.18 & -3.08 & 1.96 & -0.517 & 0.631 & -2.92 & 0.90 \\
50 & -0.818 & 0.456 & 0.907 & -4.10 & 2.43 & -0.627 & 0.759 & -3.49 & 0.90 \\
90 & -0.148 & 0.016 & 8.71 & -10.2 & 4.88 & -1.15 & 1.33 & -5.97 & 0.90 \\
\hline 0 & 0.858 & 0.506 & 15.7 & -14.5 & 6.15 & -1.34 & 1.47 & -6.29 & 0.90 \\
& 1.31 & -0.67 & 16.0 & -13.0 & 5.05 & -1.01 & 1.01 & -4.00 & 0.90 \\
& 1.31 & 0.617 & 13.3 & -9.9 & 3.47 & -0.614 & 0.527 & -1.72 & 0.90 \\
\hline
\end{tabular}

* The factor by which the numbers in the body of the table should be multiplied. 


\section{FIGURE CAPTIONS}

FIG. 1. Sensitivity of droplet absorption, $Q_{\text {abs, }}$, to cloud droplet radius, $r$, calculated using Mie code at a wavelength of $11 \mu \mathrm{m}$. Also shown are approximations to the curve for small and large droplets. (Adapted from Chý lek et al. 1992).

FIG. 2. Sensitivity of a) $\beta Q_{\mathrm{abs}}$, and b) $\beta$, to the droplet effective radius, $r_{\mathrm{e}}$. Values are derived using Mie theory for a wavelength of $11 \mu \mathrm{m}$ and measurements of 2156 cloud droplet size distributions obtained aboard the UW Convair-580 aircraft in the Arctic between 6 June and 14 June 1998.

FIG. 3. Sensitivity of cloud broadband longwave emissivity $(\varepsilon)$ to cloud droplet effective radius $\left(r_{\mathrm{e}}\right)$ and cloud liquid water path (LWP). Values derived using Mie theory and measurements of 2156 cloud droplet size distributions obtained aboard the UW Convair-580 aircraft in the Arctic between 6 June and 14 June 1998. Broadband longwave emissivity is calculated assuming a cloud temperature of $250 \mathrm{~K}$.

FIG. 4. Aerosol and cloud microphysics measurements obtained aboard the UW Convair-580 aircraft on 14 June 1998 in a flight track through the middle of an arctic stratus layer over the Chukchi Sea. There was a transition from pristine air to polluted air at a distance of about twothirds along the track.

FIG. 5. The effect of clouds on average monthly radiation fluxes at the surface in the Central Arctic (left axis) (Vowinckel and Orvig 1964). The solid line represents the annual variability in sulfate $\left(\mathrm{SO}_{4}^{2-}\right)$ aerosol concentrations measured at Alert, Canada (Sirois and Barrie 1999). 
FIG. 6. Temperature and dewpoint profiles at Barrow, Alaska, and properties of water cloud and ice precipitation measured from the UW Convair-580 aircraft over the Beaufort Sea on 3 April 1992.

FIG. 7. Derived values of the sensitivity of changes in instantaneous longwave cloud radiative forcing $\left(C R F_{\mathrm{LW}}\right)$ at the surface to a decrease in the cloud droplet effective radius $\left(r_{\mathrm{e}}\right)$, versus cloud liquid water path $(L W P)$, shown for three initial values of $r_{\mathrm{e}}$. Calculations were performed using the Streamer model (Key and Schweiger 1998) for the scenario shown in Fig. 6. The histograms show airborne measurements of the frequencies of occurrence of various values of LWP in the Arctic in (b) April (Hobbs and Rangno 1998), (c) June (Herman and Curry 1984; Tsay and Jayaweera 1984; Hobbs and Rangno 1998, 2000), and (d) October (Pinto 1998). The cases included in the histograms had cloud tops below $2 \mathrm{~km}$ and were composed exclusively of water, with, in some cases, ice crystal precipitation below (see Hobbs and Rangno 1998). 


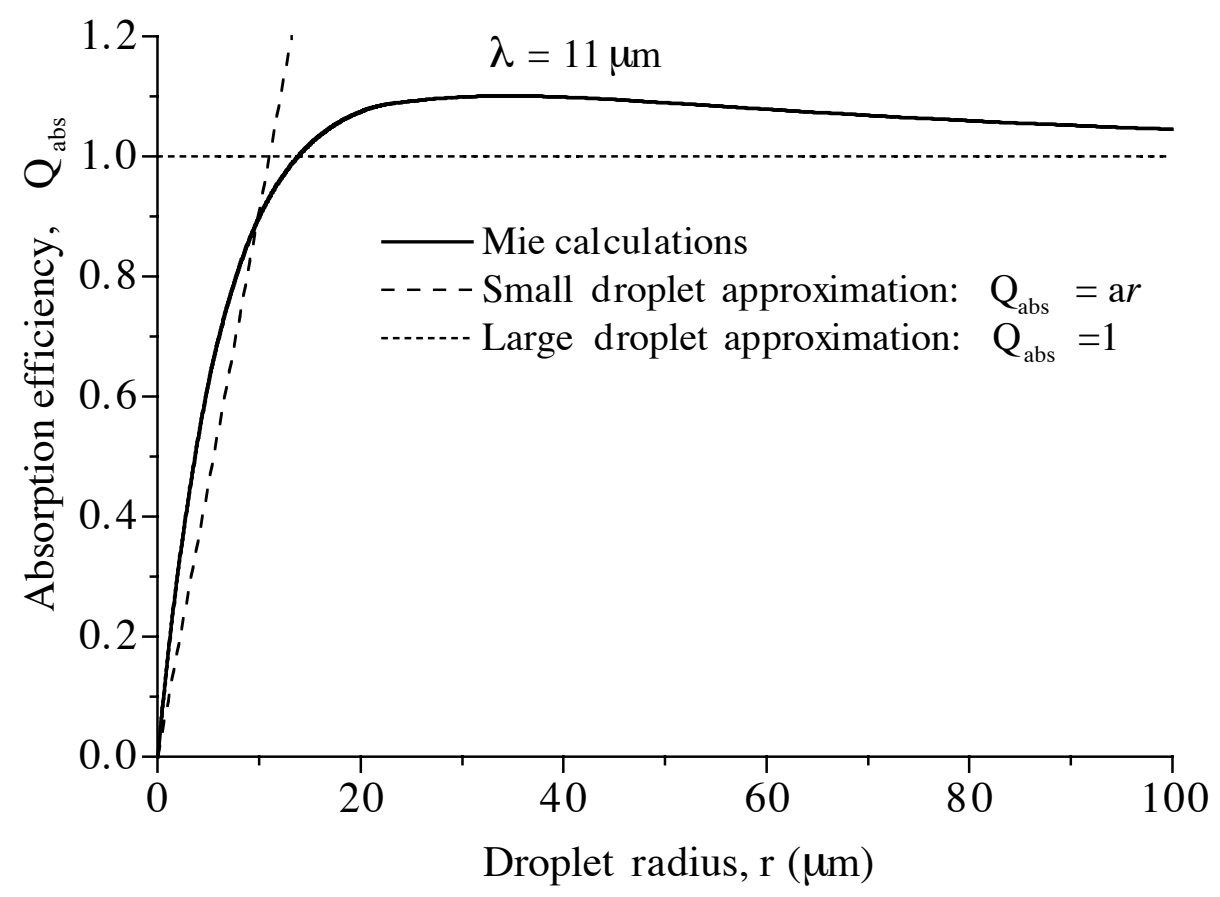

Figure 1 

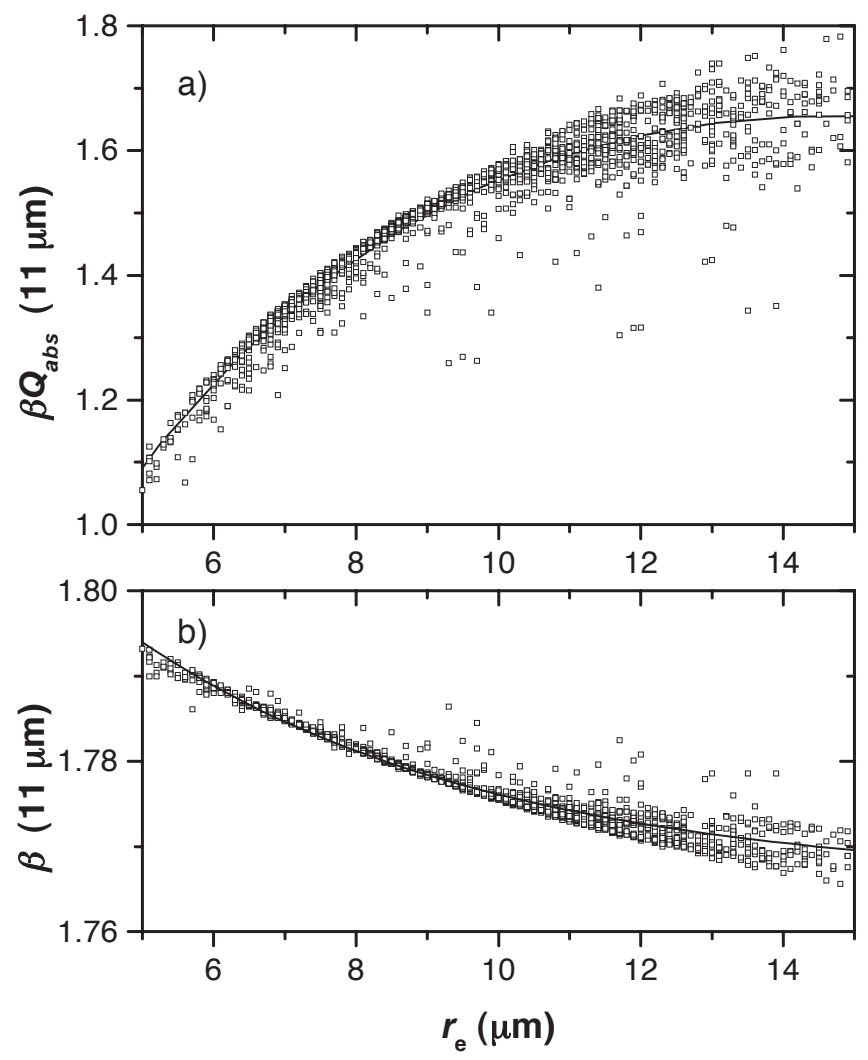

Garrett et al. Figure 2 


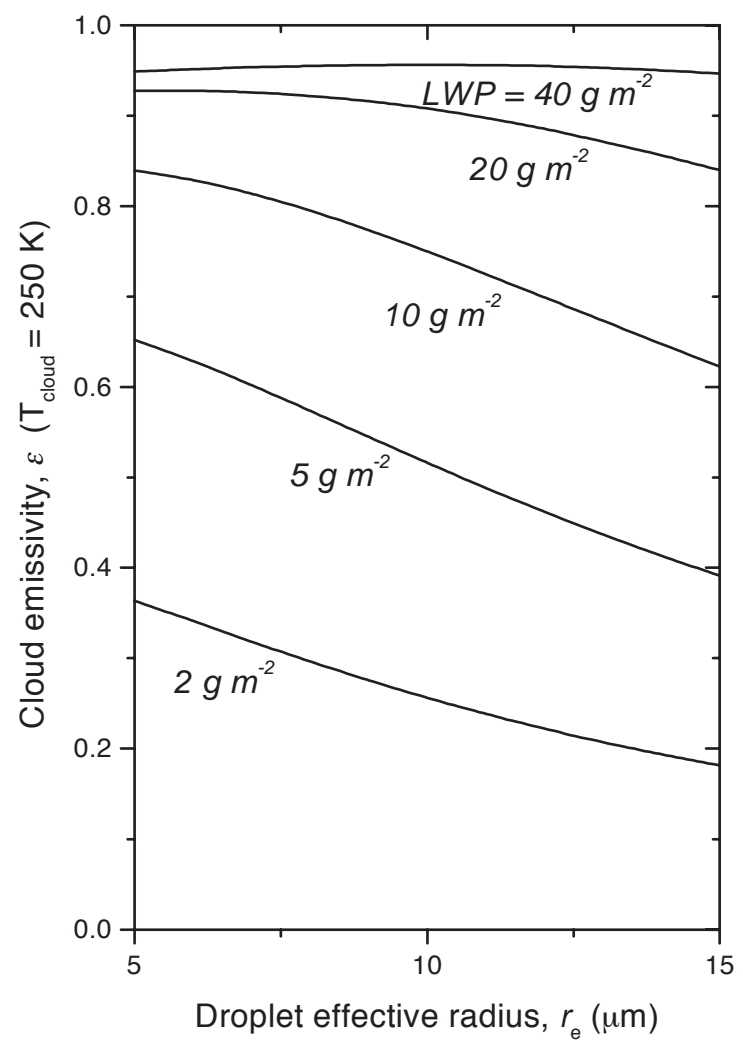

Garrett et al. Figure 3 

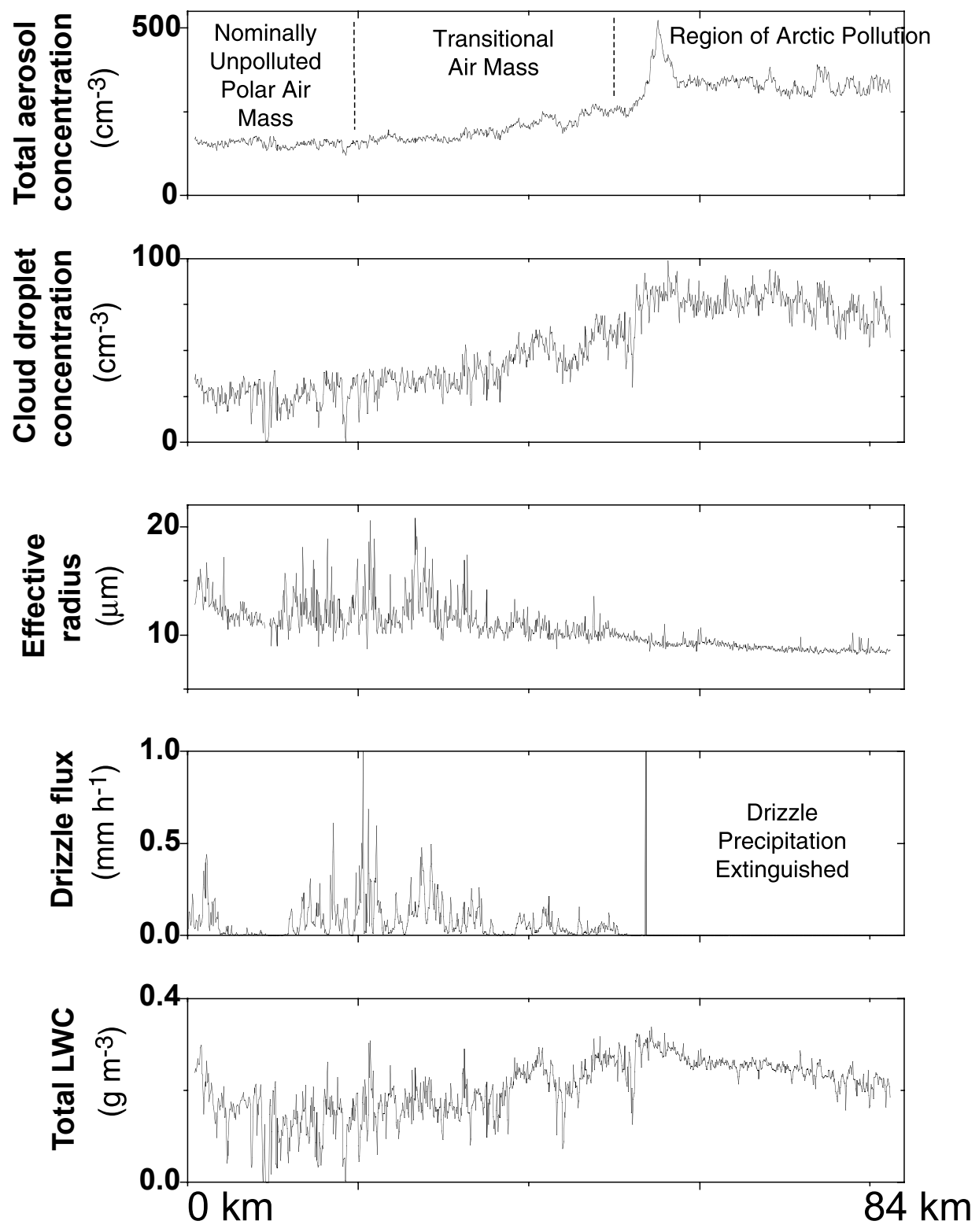

Garrett et al. Figure 4 


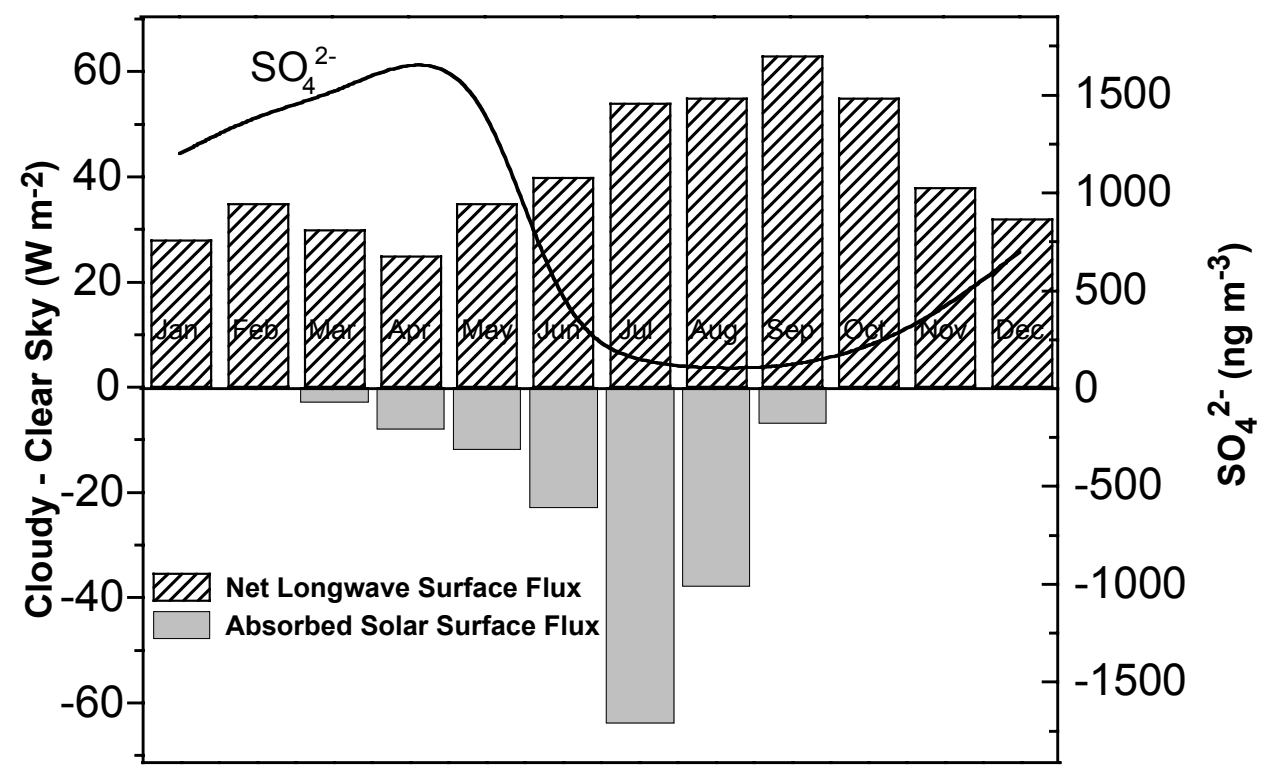

Garrett et al. Figure 5 


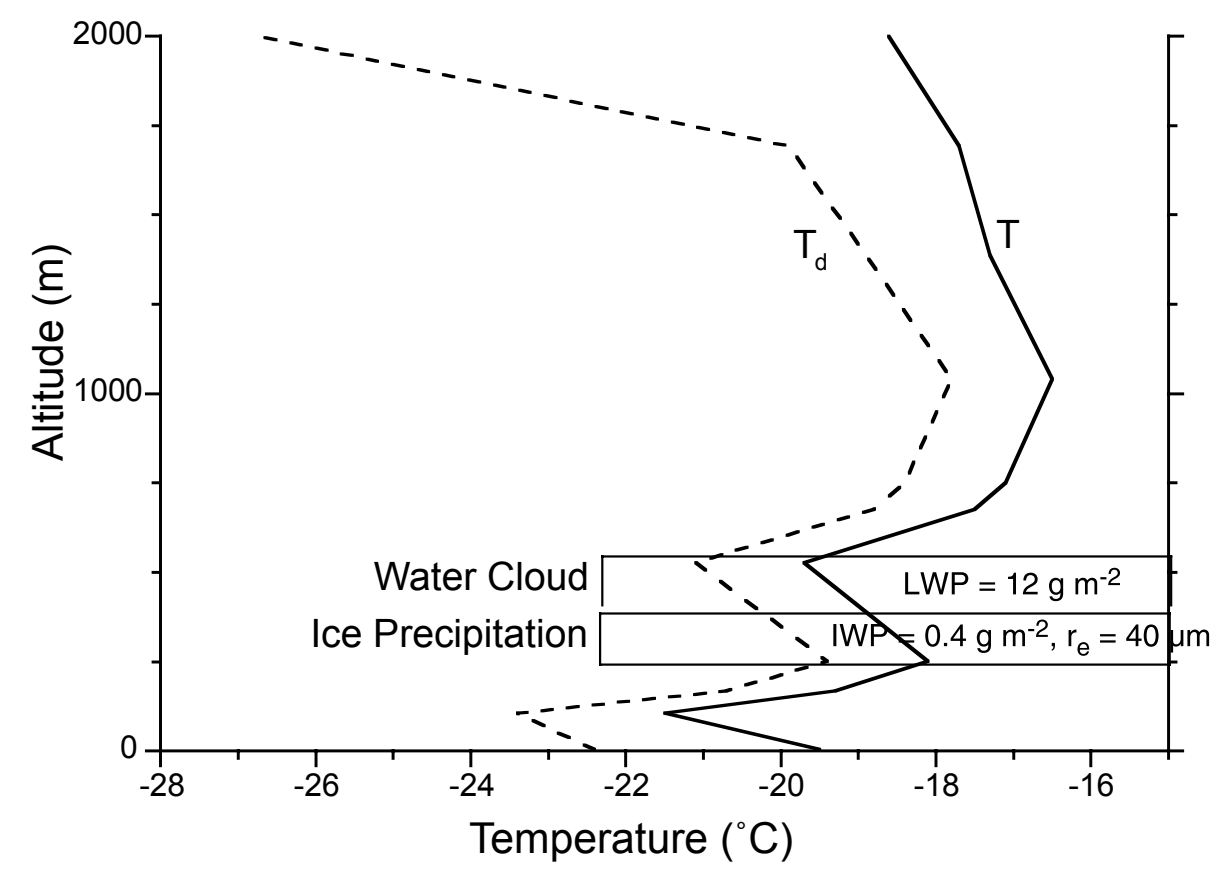

Garrett et al. Figure 6 

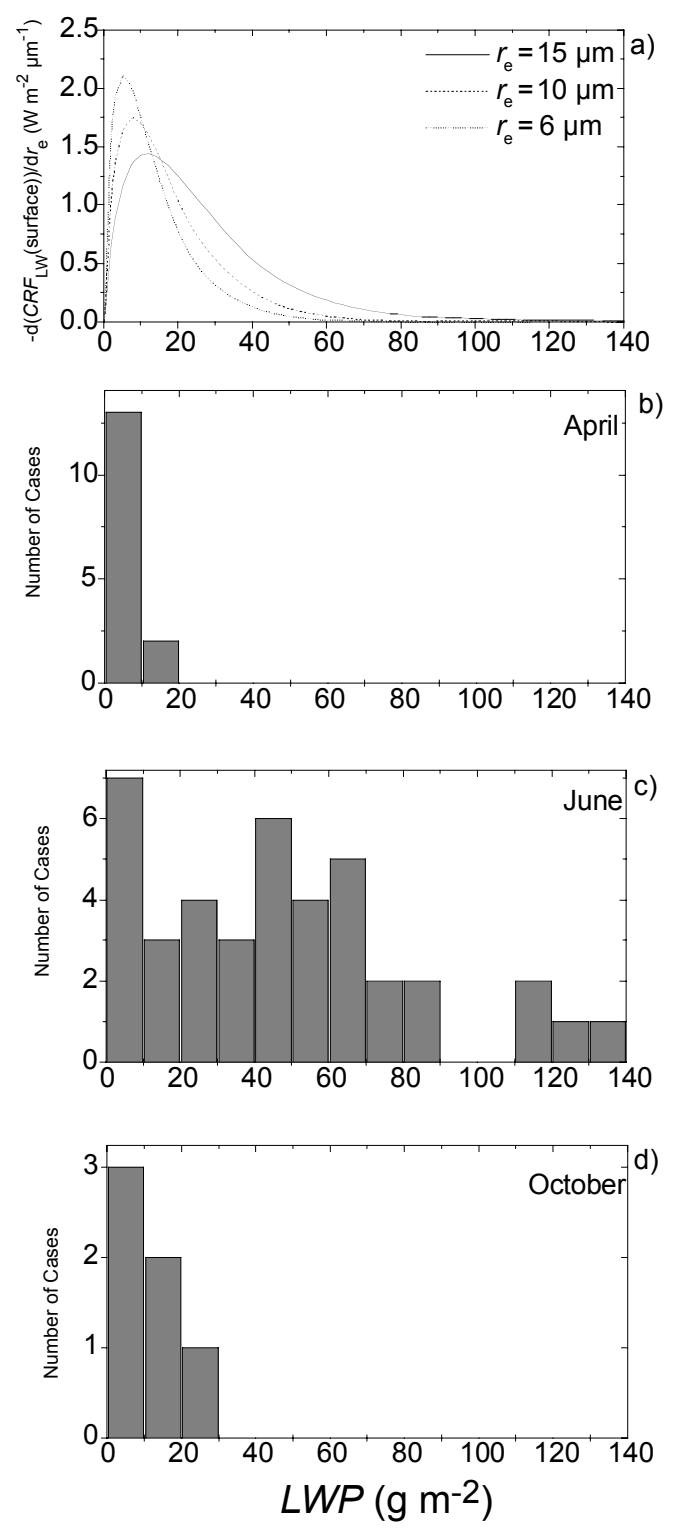

Garrett et al. Figure 7 